\title{
Logics of care in clinical education
}

\author{
Lehn-Christiansen, Sine; Holen, Mari
}

Published in:

Journal of Organizational Ethnography

DOI:

10.1108/JOE-04-2018-0021

\section{Publication date:}

2019

\section{Document Version}

Early version, also known as pre-print

\section{Citation for published version (APA):}

Lehn-Christiansen, S., \& Holen, M. (2019). Logics of care in clinical education. Journal of Organizational Ethnography, 8(3), 268-278. https://doi.org/10.1108/JOE-04-2018-0021

\section{General rights}

Copyright and moral rights for the publications made accessible in the public portal are retained by the authors and/or other copyright owners and it is a condition of accessing publications that users recognise and abide by the legal requirements associated with these rights.

- Users may download and print one copy of any publication from the public portal for the purpose of private study or research.

- You may not further distribute the material or use it for any profit-making activity or commercial gain.

- You may freely distribute the URL identifying the publication in the public portal.

\section{Take down policy}

If you believe that this document breaches copyright please contact rucforsk@kb.dk providing details, and we will remove access to the work immediately and investigate your claim. 


\section{LOGICS OF CARE IN CLINICAL EDUCATION}

Sine Lehn-Christiansen and Mari Holen

Journal of Organizational Ethnography, Vol 8 (3), August 2019

\section{Introduction}

Public sector health care in the Nordic welfare states has undergone significant changes during the last 50 years (Dahl, 2000; Wærness, 2008). Research has explored how Scandinavian care practices are currently heavily influenced by market-based dynamics and utilitarian ethics, thus setting an ideal of care as based on humanistic values under pressure (Bakken et al., 2002; Blom et al., 2017; Hansen and Kamp, 2019; Wrede et al., 2008)

In this paper, we focus on care practices in clinical education. Through analysis of nursing students, who are in the process of acquiring competencies to provide care in clinical placements, we will argue that clinical education is shaped by different logics of care. The potential in focusing on nursing students learning to care is that the logics and values that are often implicit and therefore "invisible" in care become visible in situations of learning. They become articulated, for example as "learning goals" or through teachers' corrections of students who break with or fail to live up to the values and logics inherent in professional care. In other words, students learning to care are interesting study objects when looking at care values, because they are in the midst of acquiring the values of care that are prevalent in their future care practice as professionals.

The research questions that we will pursue in this paper are: 1) Which predominant logics of care pervade care education for nurses in clinical practice? 2) How do students negotiate, adapt or reject these logics? 3) How do the different logics of care shape patient care? 
Based on our findings, we will discuss how care in contemporary Danish health care is grounded in different values - and how these can be understood as related to each other in ways that are underexplored in current research.

\section{Background}

Research into students' learning of care in clinical practice is a large and very diverse field covering many aspects related to students' accomplishment of caring competencies. Two recurrent themes are relevant to this paper.

First is the theme of empathy. Generally, the literature has as its starting point the notion that empathy is a fundamental aspect of caring related to quality and patient outcome. In a review article, Williams and Stickley (2010) point to the idea that nurse educators have a responsibility to provide an education that engenders empathic understanding in nursing students. They identify a tendency in education research to associate empathy with emotional intelligence and suggest that nursing education should promote the self-awareness that is seen as central to empathy. They hereby draw upon a concern that nursing students demonstrate a lack of empathy. Ward et al. (2012) find that, contrary to what might be expected, nursing students who have experienced more than the average number of encounters with patients display a lower level of empathy. McKenna and colleagues find that nursing students have an "acceptable level" of empathy, although the study points to room for improvement (McKenna et al., 2012). Both studies draw their conclusions on the basis of statistical data, hence illustrating the inclination to approach empathy as an, inner, psychological and measurable matter (see also Mennenga et al., 2016). 
The second theme of relevance relates to nursing students' experience of clinical care education. Pearcey and Draper suggest that student nurses are disillusioned with the reality of clinical nursing due to the amount of work to be done at the expense of patient contact and communication. Their research shows that a majority find nursing to be "not as caring as they expected" (Pearcey and Draper, 2008). Stress (Admi, 1997), role confusion (Cooper et al., 2015), a sense of not belonging (Liljedahl et al., 2016) and feelings of insecurity (Mannix et al., 2006) are prevalent in research covering students' experience of clinical placements, thus pointing toward the conclusion that clinical placement is a challenging experience. Our own research adds to the picture the finding that nursing education offers students an ambiguous socialization into the nursing profession (author reference, 2019).

\section{Methodology}

This paper is written on the basis of a four-year study (2015-2019) of clinical nursing education named ACROSS, situated at Copenhagen University Hospital (Holen and LehnChristiansen 2017, Lehn-Christiansen and Holen 2019). The overall aim of the project is to strengthen the coherence of clinical education in nursing by providing a test class of 40 nursing students extracurricular activities such as supervision and training in clinical reasoning. We are connected to the project as external, university-based researchers on the project and our commission has been to produce knowledge on the project's attempt to qualify clinical education. To do so, we have followed a class of nursing students throughout all clinical elements of their study program. We have carried out several hundred hours of ethnographic field studies in all three health care sectors and completed more than 50 interviews with nursing students, clinical preceptors and teachers. 
Field observations have been conducted in all but the first two-week clinical placement. In total, we have observed 20 students in 20 different clinical settings throughout the entire nursing program. Each observation has been carried out over two full days. We have used a combination of inquiry tools, such as reflexive field notes and on-site interviews with students and their preceptors and shadowing. As pointed out by Delgado and Cruz, shadowing is a relevant tool in multi-sited ethnography because it "provides a rich context wherein actions are produced, and it allows the researchers to be in places where they would not usually go" (2014, p. 47).

\section{The study of care as a matter of practice and logics: Methodological inspirations}

With inspiration from Dutch researchers Annemarie Mol and colleagues, we approach the study of care through nursing students' care practices. We follow Mol's understanding of care as practices aiming at "handling life with disease" (Mol, 2008, p. 2). By working with a loose concept of care practices, we have accepted the invitation to focus our analysis on "actual situations and events where people, together with their artifacts and ways of understanding the world, aim for improving or stabilizing the situation of the people or things cared for" (Ceci et al., 2017, p. 57).

This understanding does not limit the study of care to any specific doings, to certain professions or to specific contexts. Caring practices often imply a good deal of "tinkering", as Mol and colleagues Pols and Moser phrase it, to indicate the jumble of doings that constitute care practices (Mol et al., 2010). We study care practices involving nursing students. By taking this approach, we are enabled to think deliberately about the practices that constitute care and thus, hopefully, understand practices on their own terms - and not, for example. as 
opposed to "theory" as frequently happens within the field of nursing education studies (Holen and Lehn-Christiansen 2017).

Mol's idea of "logics" has proven helpful in our exploration of the care practices of nursing students. In line with Mol, we use the concept of "logic" to explore the patterns of practice that make everyday practices understandable and sometimes even "natural" to the human agents involved. A logic gives reason and appropriation to actions. Logics make some things fit together. Using the term "logic" does not imply viewing practice as coherent and logical (Mol, 2008, p. 9). Even if practices can be explained with reference to underlying logics, practices are still also fluid and complex. Unexpected events that break with the dominant logics happen all the time. We have observed nursing students doing many things that were not prescribed by the care procedures or were not in the schedule of the day in order to provide good care, such as working out the connection between a patient's hearing aids and her iPad to enable the patient to listen to podcasts while waiting for the test results. Where Mol has developed her concept of the logic of care as opposed to the logic of choice, we operate with several logics of care that permeate and become entangled in everyday care practices in nursing education. The logic of choice has not proven to be dominant in our material.

A focal argument for studies like ours is that the logics of care are often "invisible" or unconscious to the actors involved; they are embedded in the institutionalized day-to-day ways of doing and saying, the habits inherent in the professionalism, materialities and/or the governing structures of clinical practice. The study of nursing students makes it somewhat easier to identify these logics; students are often not familiar with the way things are done, but they are committed to learning. Therefore, the experience of the novice makes visible 
what is (often) obvious and therefore invisible to experienced nurses. As part of their clinical education, nursing students are provided with verbal and non-verbal support and corrections that socialize them to the institutional care practice. During this process, they are corrected by many different professional nurses, and sometimes in contradictory ways, thus making visible the rights and wrongs of the professional care practices into which they are being socialized.

Our approach to the study of values does not start from a normative definition of care. We are not interested in exploring if or how students' or preceptors' care practices measure up or fall short. Instead, we follow Pols (2015) in her description of an "empirical ethics of care" (p. 82) that articulates the forms of the good that students and their professional colleagues in clinical practice value or attempt to bring into being in their practices (Ceci et al., 2017, p. $62)$.

\section{Analysis}

In the following, we present the results of our analysis. We identified three different logics of care in clinical education: 1) the logic of relational care, 2) the logic of care education and 3) the logic of care production. As we will argue, these logics have a profound impact on the clinical education of nurses. By use of empirical examples, we seek to illustrate the workings of these logics and unfold some of their entanglements.

\section{The logic of relational care}

Let us begin by looking into student nurse Stina's clinical placement in primary care:

Today she's got four visits to elderly people. First visit is to an elderly man, who needs a urine catheter replaced. We meet Nurse Eva at the garden gate. Stina is not familiar with the procedure, so the plan is to observe Eva to find out how it's done. [...] After saying goodbye 
to Eva, we visit another male patient, who has had surgery very recently. Stina's task is to attend to his wound. The wife answers the door; she's very upset about the fact that her husband has already been discharged. And she had expected a specialist nurse and is therefore very unhappy about the entire situation. She also yells at her husband, angry that he is incapable of taking care of anything. The wife also yells at Stina, her yelling turns into tears and she apologizes. Stina comforts her. Afterwards she attends to the wound. She's not sure if it is healing satisfactorily and takes a few photos with her cell phone. Then we head toward the third visit, one more wound. [...] Back at the nurses' office, Stina talks to the wound specialist, Nurse Karen, about the wound she photographed and the upset wife. She seems shocked. Karen says that the wife was just as upset the other day when she was there. On that occasion, Karen had told the wife to leave, so that she could concentrate on the wound. She also says that she's not capable of saving the entire world, not least the bad marriages of the patients. That's somebody else's job. Stina starts to document the visit on the laptop. She consults Karen about the right way to describe the wound. She also adds a note saying that the wife is in a crisis. (Field notes)

The example gives a glimpse into the everyday life of clinical education. Stina is in the final clinical placement in primary care and is expected to be able work independently. The logic of relational care is rooted in the nurse-patient dyad concerned with the care practices related to the care needer and equivalent to Mol's definition of the logic of care (Mol, 2008). Within this logic, care is the effort to support the patient in handling life with disease. This logic can be applied to the example of Stina, who takes on the responsibility of providing the care needed by her patient and his wife in the current situation, (or at least, attempting to do so). Even though the schedule defines Stina's task as “observation of left foot wound", she relates to the entire situation, including the angry wife. 
The logic of relational care gives meaning to one of the most basic arguments underlying the idea of clinical placements as a fundamental component of care education: the need to meet and care for real patients. According to the logic of relational care, good care very much depends on the students' ability to learn how to handle the complex care situations of real patients. Another example of this is student nurse Vibe, who tells about her experience of caring for a patient:

In the beginning she wanted to stay in bed, she didn't want to eat and she didn't want to go to the toilet. But I managed to get her to join me in the dining room. We just sat there and talked. It was nice, and I could tell she enjoyed having some company. She actually ate, and I got to know more about her normal routines. She told me that she normally defecates in the evening. So we agreed that I would assist her to the bathroom at night to try to get her body back to normal. It added a lot of dignity, I think.

Vibe considers good care as connected to the establishment of a relationship to the patient and to "dignity". Vibe's caring practice makes perfect sense within the logic of relational care; she emphasizes the relational aspects and caring as depending on her getting to know and handle the patient as a unique human being.

A different example of the workings of the logic of relational care is student Agnete, whose final clinical placement is in an intensive psychiatric unit. Like Vibe, Agnete's care practices can also be understood as an expression of the logic of relational care, for example in a situation where she observes a patient who starts crying in the unit's common room. Agnete goes to the nurses' office and asks the nurse responsible for the patient to handle the situation. The nurse refuses, arguing "the patient cries all the time". Professional interference 
is useless, she says. Agnete keeps insisting that the patient needs attentive care; she should not be left to cry by herself. At last, the nurse agrees and turns to the patient. The situation can be seen as another example of the unfolding of a student's care practice based on the logic of relational care, implying that it is the responsibility of the professionals to attend to patients in their care. However, the example also illustrates that the logic of relational care is by no means the only logic involved in clinical practice. The professional nurse seems to be preoccupied with the question of "what works." and a rationality that makes practices that do not seem to work meaningless. We shall return to this in the discussion.

\section{The logic of care education}

The second logic that we identified as predominant in clinical care education is the logic of care education. This logic can be seen as an important part of the foundation of contemporary nursing education; it involves the idea that clinical education should be ruled by considerations for students' learning and ensure a certain level of competencies among new nurses. The logic of care education makes it meaningful to formally break down the overall educational goal of becoming a nurse into a large number of single components and learning outcomes on different levels. The logic of care education is also at play in the initial example of Stina. Even though she is almost a nurse, she still needs supervision when faced with new procedures or complicated tasks, such as a difficult wound or the replacement of a urine catheter. This practice of seeking professional advice is not just a trait of formal undergraduate education; it is a profound characteristic of health care practices to seek advice when in doubt. Stina is also expected to present and discuss her doings with her preceptor at the nurses' office, who will challenge her arguments and test her theoretical knowledge; her notes on today's patients will be often be examined with a double goal of patient safety and learning progression as she will be expected to take part in nursing conferences as a 
professional nurse. The logic of educational care is not solely a trait of undergraduate nurses' everyday life; it is a characteristic of professionalized nursing care practices.

Following the visit, Stina tells us that she does not have the knowledge needed to deal with wounds like the one she encountered during this visit. We ask her why she has not studied wound care during some of the so-called "study days" reserved for reading theory during clinical placement. She replies that she has been preoccupied with readings related to the thematic written assignments that she needs to submit during this placement. We also ask why she has not addressed her need for more knowledge of wound care in the hour-long reflection sessions with her preceptor. "But in these sessions we discuss cases and topics introduced by the preceptor," she argues. The logic of care education has its focus on learning outcomes related to care. It is the focus on learning products, or "outcomes" as they are termed within this logic, very often in terms of skills, knowledge and competencies, which splits learning into separate components. Following the logic of care education, there is a very close connection between stimulating the learner and the expected learning outcome. When Stina is told and shown how to replace a urine catheter, she is expected to "know about" this procedure, and to be able (or at least willing) to take on the task herself the next time. In clinical practice and among students, this practice is often spoken of as "see one, do one". It is also this rationale that makes it meaningful to student Marie to leave her patient in the middle of a conversation to go to another patient's room to see a penicillin drip in action. To "experience things," as another student phrases it, becomes equivalent to knowing in this logic. Consequently, and quite contrary to the logic of relational care, the logic of care education often considers care practices as independent of context.

\section{A regime of examination}


Clinical placement students are commonly teamed with a nurse. In general, they are not with the same nurse on more than two or three consecutive days. We have noticed how students are very frequently asked to account for their knowledge both generally and more specifically in connection with procedures, diagnoses or nursing theory during placements. These questions are posed in all settings, at all times of the day. A way to understand these constant inquiries is that it is very difficult for the regular nurses to support the professional progression of the students without being familiar with their experience and level of knowledge. The logic of care education thus establishes a regime of examination; students are asked to account for their skills and knowledge both generally ("What can you do?") and more specifically (“Do you know how a glucose drip works?”).

What we find remarkable is that this very dominant regime of examination seems to be only loosely connected to actual caring practices. In the case of Stina, we see that her challenges with wound care fall outside the formal teaching activities established by clinical education. In this particular case, Stina consults the wound specialist, so that the patient does not suffer from the student's lack of competence. However, as Stina says, "It's hard to know what you don't know." A more worrying example of this is student Marie, who does not take any action on a patient's complaints about soreness around the backbone after being in bed for several days, or student Milla, who does not feel motivated to understand the complexities of the condition of the patients she cares for and therefore does not really know what to look for when caring for her patients. She explains:

Sometimes my preceptor goes through my plan, saying “you've done that, you've done that, etc.” And I just say “yes” even though I might not actually have done it by myself. I don't know why, probably it's because I want to please them. 
This points to a care practice where instructions given to students on the one hand are systematically evaluated, but on the other hand the evaluation is disconnected from the actual care actions taken (or not) by the students. In conclusion, the logic of care education considers learning to care as controllable and measurable through tests and examinations. At the same time, the connection to the daily challenges met by the students is weakened.

\section{Active, visible caring}

Within the logic of care education, care is constituted as an assemblage of activities connected to a body of knowledge and experience of "handling Life with disease." Learning becomes equivalent to the engagement of these activities and it is therefore worrying if students are not "active" in a visible sense during clinical placement. An example of this is the case of student Marie. Her supervisor Gitte receives reports from the other nurses that Marie is "not active" and that she "sits around" too much. Marie is confronted with this at a formal study meeting. Being seen as a problematic student worries and confuses Marie very deeply ("It knocked me out. Completely") and she contemplates the possibility of dropping out, but decides to carry on, trying to "show some more initiative." Marie explains her decision as follows:

I still don't know if what I'm doing is good enough, but... I really feel that I... in some way I feel that I'm competent. It comes naturally to me. I mean with the patients and so on, you know. I love to be with them. They're the ones who keep me going, they're the reason I haven't quit. I really enjoy working with the patients.

The above quote indicates that Marie is not fully capable of meeting the demands following the logic of care education in order to be recognized as a competent student. Even though her 
preoccupation with patients and with establishing patient relationships makes perfect sense within the logic of relational care, it is not sufficient within the logic of care education.

\section{The logic of care production}

The idea of active students providing care by carrying out activities that are visible also makes sense within the logic of care production. Contrary to the logic of care, the logic of care production operates with an idea of care resources and care practices as somewhat more fixed. The logic of care production places care practices within the realm of a (public) institution, which is why this logic considers care as a service embedded in professional as well as market and organizational concerns; patients' care needs are met according to standards and with the aim of achieving "value for money". Within the logic of care production, it therefore makes very good sense to delegate a wound specialist to this particular kind of care work to ensure that the task at hand is solved by the use of the right competencies. Seen from the viewpoint of the logic of educational care, it also makes very good sense to allocate specialized competencies to a complex case. This is also the reason that it is perfectly legitimate when the wound specialist from Stina's clinical placement states that it is not her job to deal with patients' bad marriages when Stina turns to her for advice on how to deal with the crisis of her patient's wife. The logic of care production seeks to disentangle the jumble of care practices: one specialist for the wound, another for the psychological crisis.

The logic of care production can be observed in all health care sectors in the form of various efforts to provide care in cost-effective and standardized ways. An example is when student Eric explains why "his" patient has been handed over to another care team in the unit to ensure a fair distribution of "care load" based on patients' care score. The scoring and 
distribution procedure is carried out in the office every morning to ensure that the workload is equally distributed among the professionals on duty. The ward office is a key location in relation to the logic of care production; it is here that the clinical care activities are planned, distributed, evaluated and documented. The working day of the nursing students begins and ends here, and during the day several hours are spent here. It could be said that the logic of care production transforms patients into texts and tasks, and nurses into clerks.

\section{Low-skilled workers}

The logic of care production is supported by hierarchical structures in health care organizations that support a distribution of professional responsibilities, duties and lines of command. What we see is that this logic transforms new nursing students into low-skilled workers instead of learners. In order to ensure not only the quality but also the quantity of care, the hospital's care planners try to spend the resources available in the best (which in this case means "most effective") way possible. Just like the logic of care education, the production logic divides care into "simple" and "advanced" care. New students are given simple care tasks while the advanced tasks go to the experienced professionals. What we see is that students are handed tasks involving patient hygiene and the collection of basic information (temperature, blood pressure, pulse and blood saturation). As student Tina explains, "I got sick of them [the nurses in the unit] saying, 'You can start by doing the morning wash'. Then they could do something else, because morning wash isn't very exciting." This does not happen because the logic is ill-willed, it is simply out of concern for the production. Paradoxically, the tasks categorized as "simple" by the logic of care production are the ones valued the most by the logic of care. In other words, professional complexity becomes invisible when the logic of production categorizes the task as "simple". It is the logic of care production that causes students, who prioritize spending their time with 
patients, to be seen as less productive (and maybe even "problematic", as in the case of Marie). The logic of care production makes it meaningful to "punish" students who do not engage in the business of making the unit run smoothly and in accordance with an often busy schedule. In other words, the logic of care production renders care practices that cannot be ticked off in a system of documentation less valuable care.

\section{Quid pro quo}

One might think that practices rooted in the logic of care production would seem worrying to the nursing preceptors, but as already indicated, the logic of production often goes hand in hand with the logic of care education:

I usually say to them [the students] that the more they help, in quotation marks that is, the more time the daily supervisor has for guidance and for explaining things to them. Or time for them to try to do things by themselves, while the supervisor is observing. Because it usually takes a little longer for students to do things. That's why they should try to be part of the ward. And I do think that most of them learn to adapt quite quickly, they settle in and feel they belong. But of course they are responsible for their own learning, so they need to speak up. (Preceptor Gitte)

The logic of care production induces a barter mechanism into everyday clinical care education, in that students' work efforts are exchanged for preceptors' educational efforts. Clinical care practices and clinical education are split into two distinctive, mutually exclusive components of practice: a zero-sum game. Lack of resources, changes to the schedule, new or complex patients in need of extra care decrease the opportunities for learning. According to the logic of care production, a good student is a student who "takes responsibility by taking 
her share of the 'boring' work and makes the ward function," as Gitte says. Our data supports the preceptor's reflection: some students, like Hannah, quickly assimilate this logic:

Well, you need to look for it yourself. Nobody gives you anything if you just stand in the corner. You've got to show some... but of course that's what you do when you're interested. If you're ready to get busy, then you automatically get to do a lot. If you don't offer anything... I like to be given responsibility.

Through our observations of Hannah, we learn that she is liked; the nurses and her preceptor evaluate her as competent and she is offered an attractive part-time job in the unit.

Commonly, however, the students describe the practice of delegating basic care activities to them as frustrating. Some of them refer to these tasks as "boring work," implying that it is hard for them to identify the learning potential or care value of the tasks. Contrary to the logic of care and the logic of education, care practices related to patients' hygiene and the observation of basic biomedical values are referred to as "slave work," a phrase that makes sense within the logic of care production, but has no meaning within either the logic of care education or the logic of relational care.

\section{Discussion and conclusion}

The paper illustrates how nurse students juggle a number of different care logics that frame clinical education. Thus, this paper can be seen to contribute an alternative understanding of the experience of student stress and challenges related to clinical placement that is reported in the existing literature. Students are given the task of balancing the diverse demands and sometimes conflicting values inherent in the various logics as part of the process of learning to care. 
The paper supports existing research in identifying a dominant trend of market dynamics in contemporary health care (e.g., Bakken et al., 2002; Blom et al., 2017; Hansen and Kamp, 2019; Wrede et al., 2008). However, as pointed out, the logic of care production coexists with the logic of relational care, which seems to be a logic of great importance to students, who are in fact highly motivated by the relational aspects that this logic attaches to care practices. Last, but not least, the paper draws attention to the logic of care education and how it shapes not just future caregivers, but also care practices, in a way that seems underexplored in current research.

The logic of care education is, first and foremost, relevant in the exploration of students' struggles with learning to care. However, we will argue that this logic is related to a broader professional logic that is connected to the care needs of patients, as professional knowledge shaped by experience and/or research. Within this logic, no professionals know everything and care practices per se are characterized by insecurity and the unknown. This understanding is much in line with Freidson's concept of "the third logic" (Freidson, 2001). Within this logic, patients' care needs are defined as a professional task to which professionals work out an adequate solution. It is a logic that is supported by the organizational structures of the hospital, placing emphasis on health care professional managers, morning conferences and other kinds of professional sharing and knowledge building. However, often it is the medical profession and the logic of treatment that shapes the organizing principles and not the professions and logics related to care. In this respect, the logic of relational care and care practices being based on this is also marginalized from within, as an appendage to the dominant medical regime. 
Through our analysis of the three logics of care and how they unfold and entangle, we demonstrate how students embrace and defend care practices that are based on the logic of relational care; they attempt to understand and find answers to patients' care needs, even if they stretch beyond the prescribed task. Often, it is the relationships with patients that give students the highly desirable feeling of "making a difference" (author reference). However, spending time with patients and building relationships is not highly valued by the logics of care production and care education; these logics value other practices of care. Most students pick that up; they learn that professional acceptance from permanent staff comes from balancing their engagement with patients with an engagement in the daily production of care and in educational assignments - even if these have no direct relevance to the patient care they are directly involved in.

Empathy and care needs. What is really the problem?

As pointed out initially, students' ability to build patient relationships and to demonstrate empathy toward patients' care needs is problematized in current research. Our paper points to the finding that, in general, it is the conditions for forming relationships with patients, rather than students' ability to form relationships, that pose a problem. Our analysis thus offers a different perspective than the individualizing one, as we point to the challenges inherent in clinical placements. Students face mutually conflicting demands many times each day because each of the logics carries with it its own idea of "care", making it hard for the students to "do right". The issue of motivation must be addressed as a complex product of these circumstances, instead of as an inner psychological quality.

Inspired by Dahl (2017) and Ceci et al. (2017), we would like to suggest a reformulation of the question of students' empathy; maybe the problem at hand is not students' ability to read 
or emphasize with patients' care needs, but rather one related to the way that these needs can be understood and articulated in the first place. Within the logic of care, the needs of the patient are attached to the patient's "life with disease". In this understanding, care needs become an articulation of the distinctive and highly personal life of the patient. Within the logic of care production, care needs are prescribed and orchestrated through standardized care "packages". Care needs become generic and "life with disease" becomes a peripheral context of little or no relevance to professional caregivers. The understanding of care needs very much depends on the logic(s) of care prevalent in our health care institutions.

The struggle over care needs implies a struggle over care values. Different care practices are made (in)visible and (less) valuable. Our analysis points to the finding that the logic of production is quite dominant and the educational logic often works along the same lines.

On the other hand, we find it relevant to ask if the professional judgement that is represented in the logic of care education is being transformed into a logic of production. Even if marginalized, the logic of relational care is present in clinical practice as a demand from patients (Martinsen, 2000) as well as in the practices of future nurses.

Relational care is a key motivation for future caregivers (author reference). If clinical care education transforms this motivation into overly ambiguous professional identities, it could provide an answer to why so many newly qualified nurses leave clinical practice. And what about the people in need of care? If the professional carers of the future are trained to be more aware of care production than of identifying and meeting patients' unpredictable and messy care needs, what will be the implications for the care they can and will provide? We predict a continuation of the development toward caring practices where nurses deal with highly specialized care, while "basic" caring is delegated to lower-skilled care workers. This can be 
seen as the "natural" implication of our finding that the relational aspects of care are devalued in contemporary clinical practice. However, we are left with the question of how this devaluation of relational care practices is to be understood in the light of political and educational ambitions of providing not only high-quality, but also patient-centered care. Through the analysis, we have provided empirical insights into the entanglement and tensions between the three different logics that meet in clinical care education: the logic of relational care, the logic of care education and the logic of care production.

This research did not receive any specific grant from funding agencies in the public, commercial, or not-for-profit sectors. Conflicts of interest: none

\section{References}

Admi, H. (1997), "Nursing students' stress during the initial clinical experience", Journal of Nursing Education, Vol. 36 No. 7, pp. 323-327.

Bakken, R., Brinchmann, A., Haukelien, H., Kroken, H. and Vike, H. (2002), Maktens samvittighet: om politikk, styring og dilemmaer i velferdsstaten, Gyldendal, Oslo.

Blom, B., Evertsson, L. and Perlinski, M. (2017), Social and Caring Professions in European Welfare States: Policies, Services and Professional Practices, Bristol, Policy Press.

Ceci, C., Pols, A.J. and Purkis, M.E. (2017), "Privileging practices: manifesto for 'new nursing studies'”, in Foth, T., Holmes, D., Hülsken-Giessler, M.,Kreutzer, S. and Remmers, H. (Eds), Critical Approaches in Nursing Theory and Nursing Research: Implications for Nursing Practice, Göttingen, V\&R unipress, pp. 51-68.

https://doi.org/10.14220/9783737005128 
Dahl, H.M. (2017), Struggles in (Elderly) Care: A Feminist View, Palgrave Macmillan, London.

Delgado, N. and Cruz, L. (2014), "Multi-event ethnography: doing research in pluralistic settings", in Brannan, M. (Ed.), From the Ethnographic Turn to New Forms of Organizational Ethnography, Emerald Publishing Limited, pp. 43-58.

Freidson, E. (2001), Professionalism: The Third Logic, University of Chicago Press, Chicago.

Hansen, A.M. and Kamp, A. (2019), "Welfare professionals in transformation - the case of elderly care", in Hvid, H. and Falkum, E. (Eds), Work and Wellbeing in the Nordic Countries: Critical Perspectives on the World's Best Working Lives, Routledge, London and New York, Chapter 12.

Holen, M., \& Lehn-Christiansen, S. (2017). Drømmen om sammenhæng. Tidsskrift for Professionsstudier, (1), 25-35.

Lehn-Christiansen, S., \& Holen, M. (2019). Ambiguous socialization into nursing: Discourses of intimate care. Nurse Education Today, 75, 1-5. https://doi.org/10.1016/j.nedt.2019.01.002

Liljedahl, M., Björck, E., Kalén, S., Ponzer, S. and Bolander Laksov, K. (2016), “To belong or not to belong: nursing students' interactions with clinical learning environments - an observational study, BMC Medical Education, Vol. 16 No. 1, pp. 1-10. https://doi.org/10.1186/s12909-016-0721-2

Mannix, J., Faga, P., Beale, B. and Jackson, D. (2006), “Towards sustainable models for clinical education in nursing: an on-going conversation", Nurse Education in Practice, Vol. 6 No. 1, pp. 3-11. 
Martinsen, K. (2000), Øyet og kallet, Oslo, Fagbokforlaget.

McKenna, L., Boyle, M., Brown, T., Williams, B, Molloy, A., Lewis, B., and Molloy, L. (2012), "Levels of empathy in undergraduate nursing students", International Journal of Nursing Practice, Vol. 18 No. 3, pp. 246-251. doi: 10.1111/j.1440-172X.2012.02035.x

Mennenga, H.A., Bassett, S. and Pasquariello, L. (2016), "Empathy development through case study and simulation", Nurse Educator, Vol. 41 No. 3, pp. 139-142.

Mol, A. (2008), The Logic of Care: Health and the Problem of Patient Choice, Routledge, London, New York.

Mol, A., Moser, I. and Pols, J., (2010), "Care: putting practice into theory”, in Mol, A., Moser, I. and Pols, J. (Eds), Care in Practice: On Tinkering in Clinics, Homes and Farms, Transcript Verlag, Bielefeld, pp. 7-26.

Pearcey, P. and Draper, P. (2008), "Exploring clinical nursing experiences: listening to student nurses", Nurse Education Today, Vol. 28 No. 5, pp. 595-601. doi: 10.1016/J.NEDT.2007.09.007

Wærness, K. (2008), “The unheard voices of care workers and care researchers”, in Wrede, S. et al. (Eds) Care Work in Crisis. Reclaiming the Nordic Ethos of Care, Studentlitteratur, Lund, pp. 363-373.

Ward, J., Cody, J., Schaal, M. and Hojat, M. (2012), “The empathy enigma: an empirical study of decline in empathy among undergraduate nursing students", Journal of Professional Nursing, Vol. 28 No. 1, pp. 34-40. doi: 10.1016/j.profnurs.2011.10.007

Williams, J. and Stickley, T. (2010), “Empathy and nurse education”, Nurse Education Today, Vol. 30 No. 8, pp. 752-755. doi: 10.1016/j.nedt.2010.01.018

Wrede, S., Henrikson, L., Høst, H., Johansson, S. and Dybbroe, B. (Eds) (2008), Care Work in Crisis: Reclaiming the Nordic Ethos of Care, Studentlitteratur, Lund. 
[1] In Denmark, Nursing Education is organized in University Colleges, which are different from traditional universities. A Danish nursing degree course includes 90 clinical ECTS distributed into five clinical placements, the first being a two-week introductory stay in a hospital unit during the first month of the course. A ten-week hospital placement in the second half of the first year is followed by two ten-week placements in the second year in elderly care and psychiatric care. During the third year, there is a five-month placement in either a hospital, elderly care or psychiatric care. 